\title{
Determination of Total Phenols in Environmental Waters by Capillary-HPLC with U.S.E.P.A. Classified Eleven Priority Pollutant Phenols after Nitrosation and Their Visible Spectrophotometric Detection
}

\author{
Yongsoon Chung \\ Department of Chemistry, Chungbuk National University, Cheongju 361-763, Korea. *E-mail: rainbuk@chungbuk.ac.kr \\ Received November 12, 2004
}

\begin{abstract}
The determination of total phenols was accomplished by capillary-high performance liquid chromatography (capillary-HPLC) after nitrosation of the U.S.E.P.A. classified 11 priority pollutant phenols, using the nitrosated parent phenol (POHNO) as a reference for calibration. The optimum mobile phase composition for this analysis was found by examining the effect of changing the percentage of acetonitrile $(\mathrm{MeCN})$ in the mobile phase on retention factors ( $\mathrm{k}$ values) and peak intensities. As $\mathrm{MeCN}$ percentage was increased, $\mathrm{k}$ values were reduced and peak intensities were generally increased. From the results obtained, it was found that the optimum mobile phase was $90 \%(\mathrm{v} / \mathrm{v}) \mathrm{MeCN}$ solution at $\mathrm{pH} 8.0$, the detection wavelength of $400 \mathrm{~nm}$, and a detection limit (D.L., concentration at signal to noise ratio (S/N) of 3.0) of $4.5 \times 10^{-7} \mathrm{M}$. In addition, 10 of the 11 phenols present in mineral or waste water were separated after the nitrosation by capillary-HPLC. The optimum mobile phase for separation was a $40 \%(\mathrm{v} / \mathrm{v}) \mathrm{MeCN}$ solution at $\mathrm{pH} 5.0$.
\end{abstract}

Key Words : Capillary-HPLC, 11 Priority pollutant phenols, Nitrosation, Total phenols

\section{Introduction}

Priority pollutant phenols, ${ }^{1}$ which originate from such diverse sources as pesticides, ${ }^{2}$ industrial wastes, ${ }^{3}$ and water supplies $^{4}$ are highly toxic, even at low concentrations. To evaluate the risks which these compounds pose, a rapid and reliable process for their determination is therefore necessary. In European countries, the maximum admissible concentration of phenols in drinking water is $0.5 \mathrm{ppb}$ for total content and $0.1 \mathrm{ppb}$ for individual phenols. ${ }^{5}$ Therefore, the determination of phenols is of great importance in the environmentally protected area.

The official standard method for the determination of phenols in many countries is based on the oxidative coupling of phenols with 4-aminoantipyrine (4AAP) in alkaline solution in the presence of potassium ferricyanide, or with 3methyl-2-benzothiazoline hydrazone (MBTH) in the presence of ammonium ceric sulfate. ${ }^{6-8}$ These reactions primarily occur in the vacant para position. Recently, however, electrochemical (EC) detection methods via HPLC separation have also been developed, including the biamperometric method. ${ }^{9-11}$

The goal of my previous work was to determine the optimum condition required for the nitrosation of the 11 U.S.E.P.A. priority pollutant phenols. ${ }^{12}$ In the previous study, it was found that a solution containing $0.002 \mathrm{M}$ nitrite and $0.10 \mathrm{M}$ hydrochloric acid provided the optimum reaction conditions for a phenol concentration range of $1.0 \times$ $10^{-7} \sim 5.0 \times 10^{-5} \mathrm{M}$. The analytical wavelengths of the nitrosated phenol solutions in acidic solution were around $300 \mathrm{~nm}$, whereas those in basic solution were around 400 $\mathrm{nm}$. Moreover, the peak intensities of the nitrosated phenols in basic solution at $400 \mathrm{~nm}$ were 1.5-2.0 times larger than those in acidic solution at $300 \mathrm{~nm}$.

Zhao C. et al. studied total phenols determination by flowinjection analysis (FIA) with biamperometric detection. ${ }^{9}$ However, no reports on the determination of total phenols by HPLC in conjunction with UV-Visible spectrometric detection in the literature. This may be due to difficulties associated with the fact that all phenols must have same HPLC retention time and the problem of eliminating interferences at the detection wavelength.

The objective of this work was to find optimum capillaryHPLC mobile phase composition for the determination of total phenols in a nitrosated phenol solution, in which the retention times of most nitrosated and non-nitrosated phenols in capillary-HPLC are same.

\section{Experimental Section}

Apparatus. The capillary-HPLC system used for the determination of the total phenols has been described in my previous papers. ${ }^{10-15}$ The system was composed of a mobile phase reservoir, a DG1110 degaser (Sanwa Tshuso Co., Japan), a M510 pump (Waters Co., U.S.A.), a AC 400-Varaccurate micro flow processor (named splitter, LC Packings, Netherlands), a 6-way valve Cheminert $\mathrm{C}_{4}$ Rheodyne injector (injection volume of $100 \mathrm{~nL}$, Valco Co., Netherlands), a Hypersil $\mathrm{C}_{18}$ capillary column $(300 \mu \mathrm{m} 15 \mathrm{~cm}, 3$ $\mu \mathrm{m}$ particle), a K2501 UV/Visible detector (cell volume: 45 nL, Knauer Wellchrom Co., Netherlands), and a M1212 X-Y recorder (ISCO Co., Japan). A M420A pH meter (Orion Co., U.S.A.) was used to measure the $\mathrm{pH}$ of sample solutions and mobile phases.

Chemicals. MeCN (HPLC grade) used as a component of the mobile phase and the sample solutions was obtained 
from Tedia Chemical Co. INC, U.S.A. All other chemicals used as standard chemicals and the components of buffer solutions etc. were obtained from Aldrich Chemical Co. (U.S.A.), and used as supplied. Deionized-ultrapure water was obtained from a UP900 ultra pure water system supplied by Human Co., Korea.

The names of the 11 U.S.E.P.A. priority pollutant phenols are summarized as follows; phenol: $\mathrm{POH}, 2$-chlorophenol: 2ClPOH, 2-nitrophenol: 2NPOH, 4-nitrophenol: $4 \mathrm{NPOH}$, 2,4-dinitrophenol: 24diNPOH, 4-chloro-3-methylphenol: 4Cl3MPOH, 2,4-dimethylphenol: 24diMPOH, 2,4,6-trichlorophenol: 246triClPOH, 2-methyl-4,6-dinitrophenol: 2M46diNPOH, and pentachlorophenol: pentaClPOH.

Method for Preparing Sample Solutions and Mobile Phases, Separation of the 11 Phenols, and the Determination of Total Phenols. The concentrations of standard phenols stock solutions in $50 \%(\mathrm{v} / \mathrm{v}) \mathrm{MeCN}$ were $5.0 \mathrm{mM}$ except for pentaCIPOH $(0.50 \mathrm{mM})$. The nitrosated solutions of the 11 priority pollutant phenols were prepared as follows: $1.0 \mathrm{~mL}$ of the stock solutions of the 11 phenols, $10.0 \mathrm{~mL}$ of $1.0 \mathrm{M}$ hydrochloric acid, and $2.0 \mathrm{~mL}$ of $0.10 \mathrm{M}$ sodium nitrite solution were mixed and diluted to $100 \mathrm{~mL}$ with ultrapure water. The solutions were transferred to Teflon flasks, which were then put into a B480 water bath (B chi Co., Swiss) filled with water at $80 \pm 2{ }^{\circ} \mathrm{C}$. Reaction was allowed to proceed for $3 \mathrm{hrs}{ }^{12}$

The reactants were cooled to room temperature, and 10.0 $\mathrm{mL}$ sample solutions were transferred to $15 \mathrm{~mL}$ vials, neutralized by adding $0.50 \mathrm{~mL}$ of $2.0 \mathrm{M}$ sodium hydroxide, filtered through a Whatman PVDF syringe filter $(13 \mathrm{~mm}$ (i.d.), $0.45 \mu \mathrm{m}$ pore size) to remove gas bubbles, and injected into the Capillary-HPLC system.

On the other hand, the mobile phases consisted of MeCNwater solutions $(\mathrm{MeCN}:$ water $=20: 80-90: 10)$ including $0.05 \mathrm{M}$ sodium acetate (at $\mathrm{pH} 5.0$ ) or $0.05 \mathrm{M}$ tris(hydroxymethyl)aminomethane (TRIS) (at $\mathrm{pH}$ 8.0). The solutions were stirred using a USS-1 ultrasonic stirrer (Nihonseki Co., Japan) and filtered through a Milli-Pore filtering system fitted with a Milli-Pore FH-organic filter (pore size: 0.45 $\mu \mathrm{m})$.

The mobile phase was recycled; i.e., most of the mobile phase entering the splitter at a flow rate of $0.40 \mathrm{~mL} / \mathrm{min}$ by means of the Waters M510 pump was returned to the reservoir, while a small part of it flowed through the injector, capillary column, and UV-Visible spectrophotometric detector at a flow rate of $4.0 \pm 0.2 \mu \mathrm{L} / \mathrm{min}$. The detection wavelength was $300 \mathrm{~nm}$ at $\mathrm{pH} 5.0$ and $400 \mathrm{~nm}$ at $\mathrm{pH}$ 8.0. The retention factors, in the form of $\mathrm{k}$ values, were calculated using the following equation.

$$
\mathrm{k}=\left(\mathrm{t}_{\mathrm{r}}-\mathrm{t}_{0}\right) / \mathrm{t}_{0}
$$

where $t_{r}$ is the retention time of the sample and $t_{0}$ is that of mobile phase (2.20 min.).

The optimum mobile phases for the separation of phenols or for determining total phenols were found by observing the effect of changing the percentage of $\mathrm{MeCN}$ in the mobile phase on the $\mathrm{k}$ value and peak intensity. Using an optimum composition mobile phase, the calibration curve was prepared, from the peak heights of nitrosated phenol (POHNO) on chromatograms for stepwise dilutions of the standard stock solution of POHNO. The detection limit (D.L.) at a signal to noise ratio $(\mathrm{S} / \mathrm{N})$ of 3 was also determined during the calibration curve preparation.

Mineral water from the Chojeong area near Cheongju-city and waste water from the Cheongju Industrial Environmental Facilities Management Corporation spiked with the 11 priority pollutant phenols, nitrosated by the same method described in the preparation of the standard calibration reference solution, were used as sample solutions in this study. The sample solutions were prepared as follows; 0.91 or $1.82 \mathrm{~mL}$ of the nitrosated 11 priority pollutant phenols (each $5.0 \times 10^{-5} \mathrm{M}$ ) were added to $7.0 \mathrm{~mL}$ of the mineral or waste water, diluted to $10.0 \mathrm{~mL}$ with $\mathrm{MeCN}$, filtered using a PVDF syringe filter, neutralized with $2.0 \mathrm{M} \mathrm{NaOH}$ solution, and injected into the system. Percentage recoveries were calculated from the resultant chromatogram.

\section{Results and Discussion}

Capillary-HPLC System and Detection Wavelength. The capillary-HPLC system has been described in detail in my previous studies. ${ }^{10-12}$ The major advantages of this system versus general HPLC are the damping ability of the splitter and consumption of a small quantity of mobile phase by recycling (flow rate: $4.0 \pm 0.2 \mu \mathrm{L} / \mathrm{min}$.).

The $\lambda_{\max }$ values of the nitrosated and non-nitrosated 11 priority pollutant phenols appeared mainly at ca. $300 \mathrm{~nm}$ in acidic solutions, while most of them in basic solutions appeared at longer wavelengths $(c a .400 \mathrm{~nm})$ and had a larger peak intensities than those in the acidic solution. ${ }^{12}$ Therefore, the wavelengths of $300 \mathrm{~nm}$ and $400 \mathrm{~nm}$ in acidic and basic solution, respectively, were chosen as the wavelengths for the detection of these nitrosated and nonnitrosated compounds in the solution for the separation or determination of total phenols.

It was also found that the mobile phase used for total phenols determinations must be basic and a detection wavelength of $400 \mathrm{~nm}$ needed, because nitrite has an absorbance at $300 \mathrm{~nm}$ (Fig. 4).

Nitrosation. The nitrosation of the phenols may proceed according to the following reaction equation;

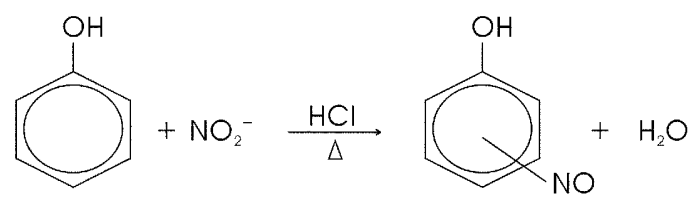

I found the optimum nitrosation condition for the 11 priority pollutant phenols in a previous work. ${ }^{12}$ It was 0.002 $\mathrm{M}$ sodium nitrite, $0.10 \mathrm{M}$ hydrochloric acid, and $3 \mathrm{hrs}$. of reaction time at $80^{\circ} \mathrm{C}$.

The nitrosation proceeded favorably, except in the case of nitro-derivatives, 246triClPOH, and pentaClPOH. The nitro- 


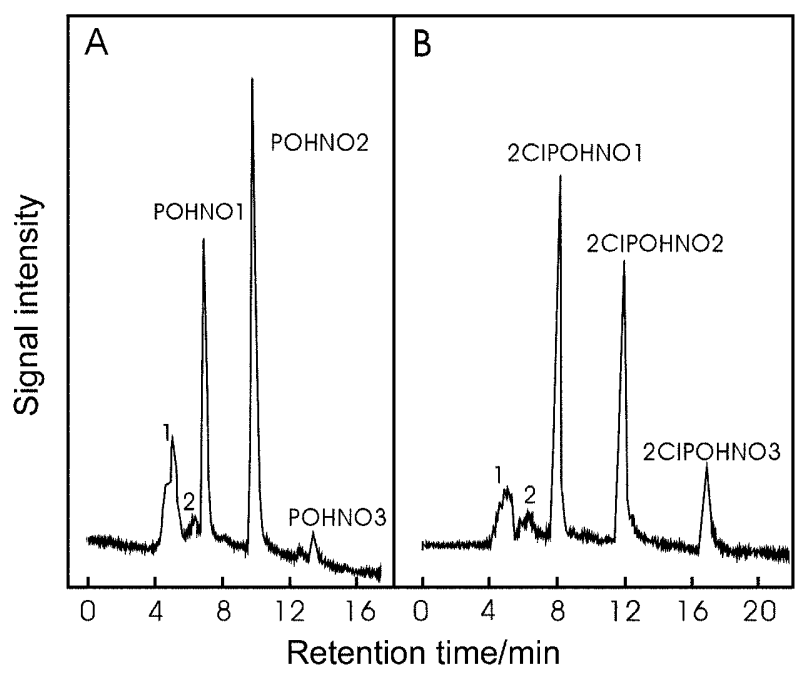

Figure 1. Chromatograms of POHNO and 2ClPOHNO. ${ }^{a}{ }^{a}$ Mobile phase; $45 \%(\mathrm{v} / \mathrm{v}) \mathrm{MeCN}$ at $\mathrm{pH}$ 5.0, Identification; 1: $\mathrm{NO}_{2}{ }^{-}, 2$ : $\mathrm{HNO}_{2}$., The concentrations of $\mathrm{POHNO}$ and $2 \mathrm{ClPOHNO}$ were 2.38 $\times 10^{-5} \mathrm{M}$, respectively.

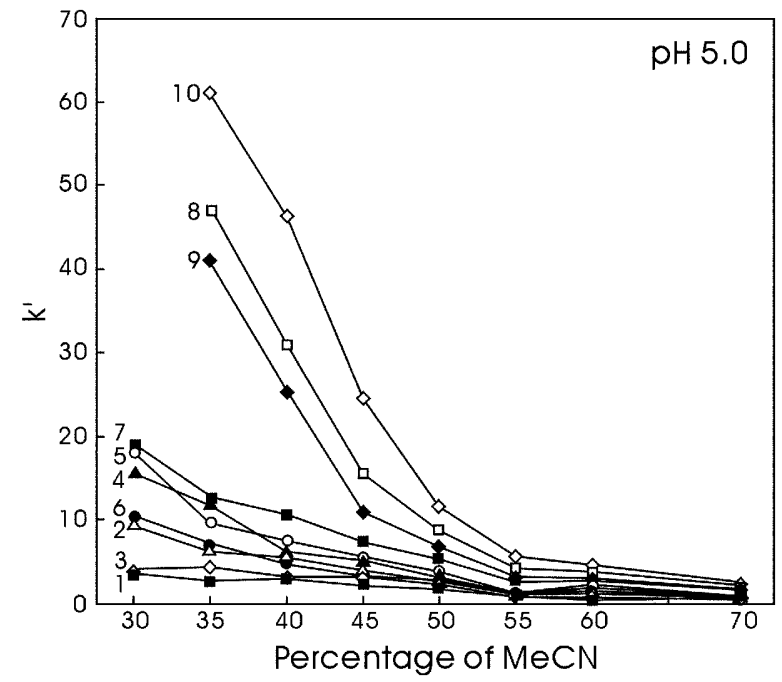

sated phenols from here onwards will be referred to as follows; nitrosated-POH: $\mathrm{POHNO}$, nitrosated-2ClPOH: 2ClPOHNO, nitrosated-4Cl3MPOH: 4Cl3MPOHNO, nitrosated-24diClPOH: 24diClPOHNO, and nitrosated-24diMPOH: 24diMPOHNO.

The nitrosated products of $\mathrm{POH}$ and $2 \mathrm{CIPOH}$ corresponded to three peaks each in the capillary-HPLC chromatograms (Fig. 1). These three peaks of the nitrosated products of $\mathrm{POH}$ and $2 \mathrm{ClPOH}$ were marked in subsequent chromatograms and descriptions as $\mathrm{POHNO}$, $\mathrm{POHNO} 2$, and $\mathrm{POHNO}$, and $2 \mathrm{ClPOHNO} 1,2 \mathrm{ClPOHNO} 2$, and $2 \mathrm{ClPOHNO}$, respectively. It is thought that these peaks correspond to the isomers of the nitrosated derivatives.

Effect of the Percentage of $\mathrm{MeCN}$ on the $k$ Value and Peak Intensity. The effect of changing the percentage of $\mathrm{MeCN}$ in the mobile phase on the $\mathrm{k}$ value and peak intensity was studied. The results are shown in Figs. 2 and 3, respectively. The $\mathrm{k}$ values of the samples decreased with increasing percentage of $\mathrm{MeCN}$ (Fig. 2), whereas the peak intensities were generally increased, except in the case of

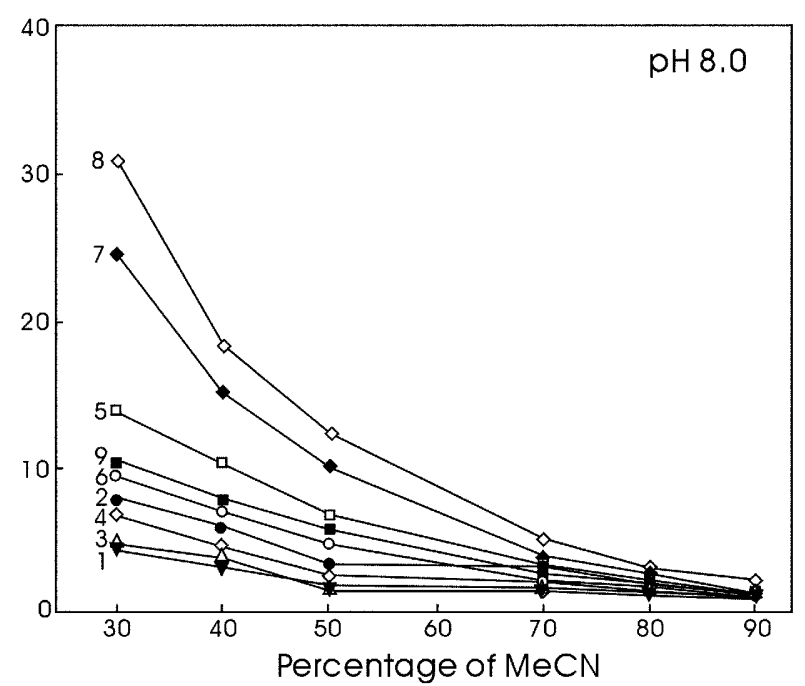

Figure 2. Effect of percentage of $\mathrm{MeCN}$ in mobile phase on $\mathrm{k}$ values at $\mathrm{pH} 5.0$ and $\mathrm{pH}$ 8.0. ${ }^{a}{ }^{a}$ Capillary column; Hypersil $\mathrm{C}_{18}(300 \mu \mathrm{m} \times 15$ $\mathrm{cm}$ ), Recording voltage; $20 \mathrm{mV}$ at $\mathrm{pH} 5.0$ and $50 \mathrm{mV}$ at $\mathrm{pH} 8.0$, Temperature; $20{ }^{\circ} \mathrm{C}$, Identification; 1: POHNO1, 2: POHNO2, 3: 2ClPOHNO1, 4: 2ClPOHNO2, 5: 2NPOH, 6: 4NPOH, 7: 24diNPOH, 8: 24diMPOHNO, 9: 2M46diNPOH, 10: 246 triClPOH.
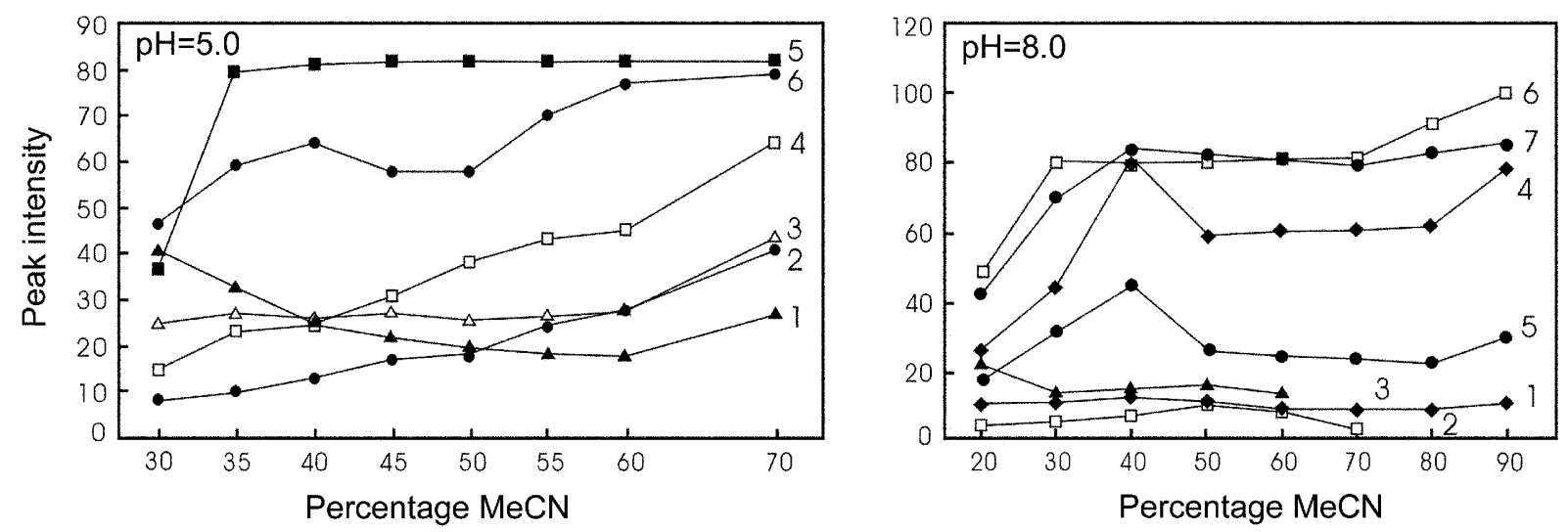

Figure 3. Effect of $\mathrm{MeCN}$ percentage in mobile phase on peak intensity at $\mathrm{pH} 5.0$ and $\mathrm{pH} 8.0{ }^{a}{ }^{a}$ The capillary column, recorder voltage, and temperature were same as in Figure 2. Identification; 1: POHNO1, 2: POHNO2, 3: 2ClPOHNO1, 4: 2CIPOHNO2, 5: 4NPOH, 6: 2M46diNPOH, 7: 24diNPOH. 
POHNO1 at $\mathrm{pH} 5.0$, and $\mathrm{POHNO} 2$ and 2ClPOHNO2 at $\mathrm{pH}$ 8.0 (Fig. 3).

The effect of changing the percentage of $\mathrm{MeCN}$ in mobile phase on $\mathrm{k}$ values and peak intensities of the nitrosated 11 priority pollutant phenols was examined at $\mathrm{pH} 5.0$ and 8.0. Of these two $\mathrm{pH}$ values, $\mathrm{pH} 8.0$ was chosen as the optimum ( $\left.\lambda_{\max }: 400 \mathrm{~nm}\right)$ to avoid nitrite peak interference at the detection wavelength of $300 \mathrm{~nm}$ (at $\mathrm{pH} 5.0$ ).

The determination of total phenols by capillary-HPLC requires that all phenols have same $\mathrm{k}$ value. By using $90 \%$ $(\mathrm{v} / \mathrm{v}) \mathrm{MeCN}$ at $\mathrm{pH} 8.0$ as a mobile phase, nitrite has no peak, the $\mathrm{k}$ values of 8 of the 11 nitrosated or non-nitrosated priority pollutant phenols were same, and higher peak intensities for the compounds were observed with lower $\mathrm{k}$ values, which implies sensitivity and a lower D.L. (Figs. 2 and 3). Solutions contain more than $90 \%(\mathrm{v} / \mathrm{v})$ of $\mathrm{MeCN}$ in mobile phase was difficult to prepare, because the $\mathrm{pH}$ of the solution must become 8.0 (pH limit of the column use) by adding aqueous buffer solution. The two compounds, 246triClPOH and pentaClPOH, do not absorb light at 400 $\mathrm{nm}$, and 24diMPOHNO has a slightly larger $\mathrm{k}$ value than the 8 compounds.

Capillary-HPLC Response Factors of Individual Phenols. The responses to $4.6 \times 10^{-5} \mathrm{M}$ of the phenols after nitrosation were recorded using $90 \%(\mathrm{v} / \mathrm{v}) \mathrm{MeCN}(\mathrm{pH} 8.0)$ as the mobile phase. The results obtained, relative to that for the parent POHNO are listed in Table 1, where response to POHNO is set as $100 \%$. The response factors for the different substituted phenols varied from 8 to $655 \%$, because the degree of substitution and its type and position have important effect on absorbance at $400 \mathrm{~nm}$.

Table 1 shows the absorbance response factors of 9 priority phenols after nitrosation by capillary-HPLC and the values were compared with the method by FIA with biamperometric detection and 4AAP-derivatization with visible spetrophotometric detection. Among these methods, it was found that capillary-HPLC method was more sensitive

Table 1. Comparison of response factors obtained for the eleven priority pollutant phenols by capillary-HPLC with spectrometric detection after nitrosation, method by FIA with biamperometric detection, and method by 4AAP-derivatization with visible spectrophotometric detection $^{a}$

\begin{tabular}{lccc}
\hline \multirow{2}{*}{ Phenols } & \multicolumn{3}{c}{ Response factor $\%$} \\
\cline { 2 - 4 } & $\begin{array}{c}\text { Capillary-HPLC } \\
\text { after nitrosation }^{a}\end{array}$ & $\begin{array}{c}\text { FIA with } \\
\text { biamperometry }^{b}\end{array}$ & 4AAP $^{c}$ \\
\hline POH & 100 & 100 & 100 \\
$2 \mathrm{ClPOH}$ & 375 & 88 & 65 \\
$2 \mathrm{NPOH}$ & 18 & 63 & 5 \\
$4 \mathrm{NPOH}$ & 40 & 40 & $<1$ \\
$24 \mathrm{diClPOH}$ & 35 & - & - \\
$24 \mathrm{diNPOH}$ & 420 & - & - \\
4Cl3MPOH & 54 & - & - \\
24diMPOH & 8 & - & - \\
2M46diNPOH & 655 & - & - \\
\hline
\end{tabular}

${ }^{a}$ Mobile phase: $90 \%(\mathrm{v} / \mathrm{v}) \mathrm{MeCN}$ at pH 8.0, ${ }^{b}$ Ref. $9,{ }^{c}$ Ref. $7 \& 9$.
Table 2. Influence of foreign chemical species on the peak intensity of $2.38 \times 10^{-5} \mathrm{M}$ POHNO

\begin{tabular}{cl}
\hline $\begin{array}{c}\text { Tolerance limit } \\
\text { (Chemical species/POHNO) }\end{array}$ & \multicolumn{1}{c}{ Chemical species } \\
\hline 1000 & $\mathrm{~F}^{-}, \mathrm{Cl}^{-}, \mathrm{SO}_{4}{ }^{2-}, \mathrm{PO}_{4}{ }^{3-}, \mathrm{Cu}(\mathrm{II}), \mathrm{Fe}(\mathrm{II})$, \\
& $\begin{array}{l}\mathrm{Zn}(\mathrm{II}), \mathrm{Ca}(\mathrm{II}), \text { Aniline, Formaldehyde } \\
\text { Sodium dodecylsulfonate }\end{array}$ \\
\hline
\end{tabular}

than the others and response factors of $2 \mathrm{ClPOHNO}$, 24diNPOH, and 2Mdi46NPOH in caillary-HPLC method are particulary large.

Interferences. The tolerance of this method to foreign chemical species, such as $\mathrm{F}^{-}, \mathrm{Cl}^{-}, \mathrm{Cu}(\mathrm{II})$ ion, $\mathrm{Fe}(\mathrm{II})$ ion, $\mathrm{Zn}$ (II) ion, aniline, formaldehyde, sodium dodecylsulfonate etc., typically found in water samples was investigated using $2.38 \times 10^{-5} \mathrm{M}$ POHNO standard solution (Table 2). The tolerance limit was defined as the molar ratio of additive to POHNO in the solution causing less than $5.0 \%$ relative error. The tolerance of the developed method to these chemical species was studied using the mineral and waste water spiked with the POHNO solution in this study. As shown in Table 2, aniline, fomaldehyde, and most of the ions tested did not interfere with the determination of total phenols. Positive interference due to sodium dodecylsulfonate was observed at a concentration was $>2.38 \times 10^{-4} \mathrm{M}$. For analysis of samples containing large amount of sodium dodecylsulfonate (SDS), SDS can be eliminated by passing the sample solution through a small anion exchange column after acidification and before nitrosation.

Separation of Each Compounds and Determination of Total Phenols. As shown in Figure 4, the separation of the 11 phenols with $40 \%(\mathrm{v} / \mathrm{v}) \mathrm{MeCN}$ at $\mathrm{pH} 5.0$ as a mobile phase was accomplished without any interference by nitrite or nitrous acid, which eluted before the 11 phenols. Although two compounds, POHNO2 and 2M46diNPOH, had the same retention time, most of the compounds were successfully separated.

As a consequence of the separation, it was found that the elution order of the 13 compounds was as follows; POHNO1

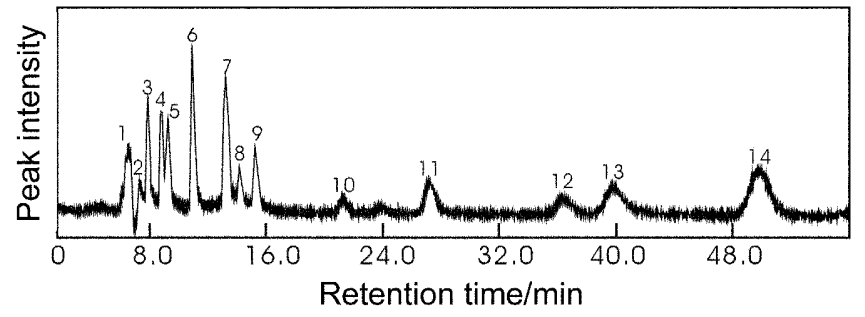

Figure 4. Capillary-HPLC chromatogram of the 11 priority pollutant phenols after nitrosation. ${ }^{a}{ }^{a}$ The capillary column, recorder voltage, and temperature were same as in Figure 2. Mobile phase: $40 \%(\mathrm{v} / \mathrm{v}) \mathrm{MeCN}$ at $\mathrm{pH} 5.0$, Conc. of individual compound in sample solution: $9.1 \times 10^{-6} \mathrm{M}$, Identification; $1: \mathrm{NO}_{2}^{-}, 2: \mathrm{HNO}_{2}, 3$ : POHNO1, 4: 2ClPOHNO1, 5: 24diNPOH, 6: 4NPOH, 7: POHNO2+2Mdi46NPOH, 8: 2ClPOHNO2, 9: 2NPOH, 10: 2ClPOHNO3, 11: 24diClPOHNO, 12: 4Cl3MPOHNO, 13: 246triClPOH, 14: 24diMPOHNO. 


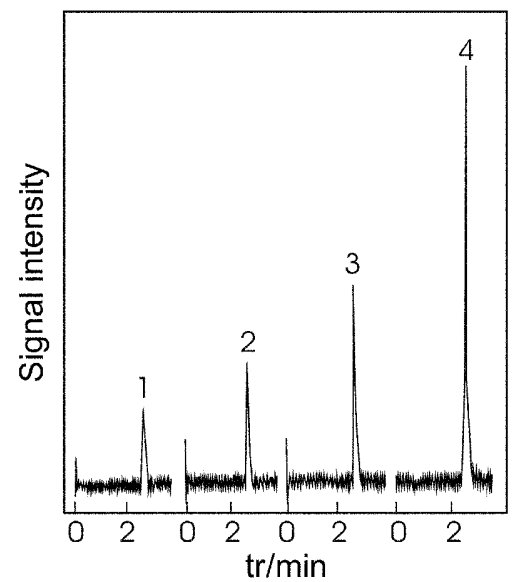

Figure 5. Capillary-HPLC chromatograms of the various concentrations of POHNO for the calibration curve ${ }^{a}{ }^{a}$ Concentration; 1 : $9.10 \times 10^{-7} \mathrm{M}, 2: 1.50 \times 10^{-6} \mathrm{M}, 3: 2.50 \times 10^{-6} \mathrm{M}, 4: 5.20 \times 10^{-6} \mathrm{M}$, Recording voltage: $20 \mathrm{mV}$, Mobile phase: $90 \%(\mathrm{v} / \mathrm{v}) \mathrm{MeCN}$ at $\mathrm{pH}$ 8.0, The others are same as in Figure 2.

$<2 \mathrm{ClPOH} 1<24$ diNPOH $<4 \mathrm{NPOH}<\mathrm{POHNO} 2 \approx$ $2 \mathrm{M} 46$ diNPOH $<2$ ClPOHNO2 $<2 \mathrm{NPOH}<2 \mathrm{ClPOHNO} 3$ $<24$ diClPOHNO $<246$ triClPOH $<24$ diMPOH $<$ pentaClPOH.

When estimating total phenols, POHNO was chosen as the reference for calibration, ${ }^{9}$ because the sample solutions were nitrosated. The optimum mobile phase for the determination of total phenols in the present study was $90 \% \mathrm{MeCN}$ at $\mathrm{pH}$ 8.0. The $\mathrm{k}$ values of 8 of the 11 phenols were same and peak intensities were sufficiently high to allow the sensitive determination of total phenols with the mobile phase.

For standard solutions of POHNO ranging from $4.5 \times 10^{-7}$ $\mathrm{M}$ to $2.38 \times 10^{-5} \mathrm{M}$, a calibration curve was prepared, and total phenols in mineral and waste water were measured by

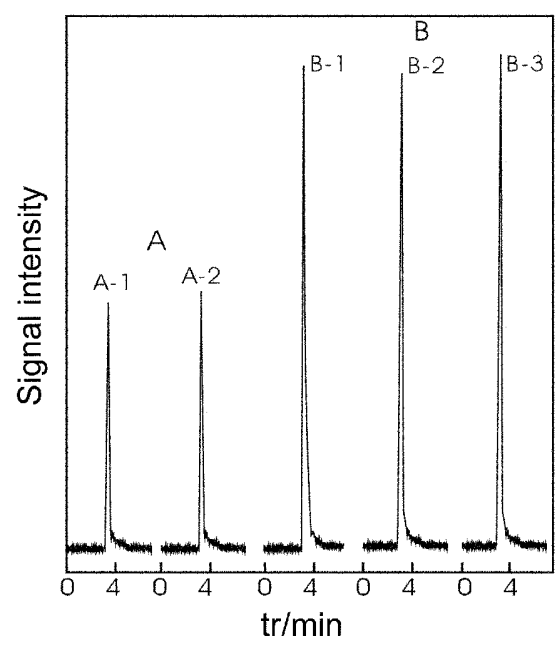

Figure 6. Capillary-HPLC chromatograms of the eleven priority phenols after nitrosation for total phenols determination. ${ }^{a}{ }^{a}$ Sample solutions: mineral water (A-1, B-1) and waste water (A-2, B-2, and B-3) spiked as individual concentrations were $4.6 \times 10^{-6} \mathrm{M}(\mathrm{A})$ and $9.4 \times 10^{-6} \mathrm{M}(\mathrm{B})$, Mobile phase: $90 \%(\mathrm{v} / \mathrm{v}) \mathrm{MeCN}$ at $\mathrm{pH} 8.0$ at 15 ${ }^{\circ} \mathrm{C}$, The capillary column and recorder voltage were same as in Figure 2.
Table 3. Determination of total phenols in mineral and waste water spiked with the eleven U.S.E.P.A. priority pollutant phenols after nitrosation $^{a}$

\begin{tabular}{|c|c|c|c|c|c|}
\hline \multicolumn{2}{|c|}{$\begin{array}{l}\text { Sample } \\
\text { solution }\end{array}$} & $\begin{array}{c}\text { Spiked conc. } \\
\text { of POHNO } \\
\quad / 10^{-5} \mathrm{M}\end{array}$ & $\begin{array}{c}\text { Found conc. } \\
\text { of POHNO } \\
110^{-5} \mathrm{M}\end{array}$ & $\begin{array}{c}\text { Recovery } \\
\%\end{array}$ & \multirow[t]{2}{*}{$\begin{array}{c}\text { Average } \\
\%\end{array}$} \\
\hline \multirow{3}{*}{$\begin{array}{c}\text { Mineral } \\
\text { water }\end{array}$} & Std. & 1.350 & 1.350 & 100.0 & \\
\hline & 1 & 1.350 & 1.370 & 101.8 & \multirow{2}{*}{102.1} \\
\hline & 2 & 1.350 & 1.381 & 102.3 & \\
\hline \multirow{4}{*}{$\begin{array}{l}\text { Waste } \\
\text { water }\end{array}$} & Std. & 2.800 & 2.800 & 100.0 & \\
\hline & 1 & 2.800 & 2.904 & 103.7 & \multirow{3}{*}{102.5} \\
\hline & 2 & 2.800 & 2.786 & 99.5 & \\
\hline & 3 & 2.800 & 2.926 & 104.5 & \\
\hline
\end{tabular}

${ }^{a}$ Each value is the average of triplicate injections, Standard deviation(\%) $=2.3$.

using $90 \% \mathrm{MeCN}(\mathrm{v} / \mathrm{v})$ at $\mathrm{pH} 8.0$ as the mobile phase. Figure 5 shows capillary-HPLC chromatograms of four concentrations of standard POHNO solutions for the preparing of the calibration curve of total phenols determinations.

The results of total phenols determination performed, using 90\% MeCN as the mobile phase are shown in Figure 6 and Table 3. The sample solutions used were mineral and waste water spiked with the 11 priority phenols(individual concentrations: $4.6 \times 10^{-6} \mathrm{M}$ [Fig. $\left.6(\mathrm{~A})\right]$ or $9.4 \times 10^{-6} \mathrm{M}$ [Fig. 6(B)]). The peak used to determine total phenols appeared as a single on the chromatograms as can be seen in Figures 5 and 6, whereas the peak by 24diMPOHNO did not appear. It is known that the three compounds, 24diMPOH, 246triClPOH, and pentaClPOH, exist in drinking and waste water only as an infinitesimal concentrations. ${ }^{16,17}$ Therefore, it is believed that the determination of total phenols was not influenced by the absence of these compounds. If one analyst hope to analyze these compounds in drinking water, he must use $60 \% \mathrm{MeCN}$ at $\mathrm{pH} 5.0$ as a mobile phase to detect them. Thus, the determination of total phenols using $90 \% \mathrm{MeCN}$ at $\mathrm{pH} 8.0$ as the mobile phase for capillaryHPLC is feasible.

The D.L., which was defined as the concentration of POHNO producing an $\mathrm{S} / \mathrm{N}$ of 3 , was $4.5 \times 10^{-7} \mathrm{M}(0.038$ $\left.\mathrm{mg} \cdot \mathrm{L}^{-1}\right)$. This value is similar to that determined for a method by FIA with biamperometric detection $\left(4.0 \times 10^{-7}\right.$ M) (Table 1). Although a lower D.L. $\left(0.005 \mathrm{mg} \cdot \mathrm{L}^{-1}\right)$ could be obtained with a method by 4AAP-derivatization with visible spectrophotometric detection ( $\lambda$ max: 470 or 509 $\mathrm{nm}),{ }^{18}$ this method is difficult to use in capillary-HPLC, because the derivatizing reagent (4AAP) and oxidizing reagent $\left(\mathrm{K}_{3} \mathrm{Fe}(\mathrm{CN})_{6}\right)$ might interfere with the detection.

Usually, the recovery test is used to study the accuracy of analytical results in water-quality control. In the present study, this test was performed by spiking with different quantities of nitrosated phenol standard solution to the two mineral water and three waste-water samples. Percentage recoveries in total phenols obtained from the mineral and waste water samples were compared with those obtained from standard sample solutions in ultra-pure water. The 
results are shown in Figure 6 and Table 3. It was apparent that the percentage recovery of total phenols in spiked mineral and waste-water samples was sufficiently accurate. The standard deviation of the recovery was $2.3 \%$.

\section{Conclusion}

This work describes a sensitive capillary-HPLC method for the continuous determination of phenols in environmental mineral and waste-water. The major advantage of capillary-HPLC was consumption of a small quantity of mobile phase (flow rate: $4.0 \pm 0.2 \mu \mathrm{L} / \mathrm{min}$.) by recycling. The optimum mobile phase for the determination of the total phenols was found by examining the effect of changing the percentage of $\mathrm{MeCN}$ in the mobile phase on $\mathrm{k}$ values and peak intensities of the nitrosated 11 phenols. As MeCN percentage was increased, $\mathrm{k}$ values were decreased and peak intensities were generally increased. The optimum mobile phase was found to be $90 \%(\mathrm{v} / \mathrm{v}) \mathrm{MeCN}$ at $\mathrm{pH}$ 8.0. Its D.L. $(\mathrm{S} / \mathrm{N}=3)$ using $\mathrm{POHNO}$ as a reference was $4.5 \times 10^{-7} \mathrm{M}$. The standard deviation of the recovery on total phenol determination was $2.3 \%$.

Additionally, 10 of the 11 phenols were separated, using $40 \%(\mathrm{v} / \mathrm{v}) \mathrm{MeCN}$ solution at pH 5.0 as mobile phase.

\section{References}

1. Sampling and Analysis Procedures for Screening of Industrial
Effluents for Priority Pollutants, U.S.E.P.A.; Environmental Monitoring and Support Laboratory: Cincinnatti, OH, 1977.

2. Cremlyn, R. Pesticides: Preparation and Mode of Action; Wiley: Chichester, 1978.

3. Lindström, K.; Nordin, J. J. Chromatogr. 1976, 128, 13.

4. Abrahamsson, K.; Xie, T. M. J. Chromatogr. 1983, 279, 199.

5. Drinking Water Directive 80/778/EEC; Commission of the European Communities: Brussels, 1980.

6. American Public Health Association: Standard Methods for the Examination of Water and Waste Water, 16th ed.; Washington, D.C., 1985; part 510.

7. Koppe, P.; Dietz, F.; Traud, J.; Robelt, C. Fresenius J. Anal. Chem. 1977, 285, 1.

8. Frenzel, W.; Oleksy-Frenzel, J. Anal. Chim. Acta 1992, 261, 253.

9. Zhao, C.; Song, J.; Zhang, J. Anal. Bioanal. Chem. 2002, 374, 498.

10. Masque, N.; Pocurull, E.; Marce, R. M.; Borrull, F. Chromatographia 1998, 47(3/4), 176

11. Ruana, J.; Urbe, I.; Borrull, F. J. Chromatogr. A 1993, 655, 217.

12. Chung, Y.; Lee, S.; Motomizu, S. Anal. Sci. \& Tech. 2004, 17(6), 393.

13. Chung, Y.; Lee, K. Microchem. J. 2001, 69, 143.

14. Chung, Y.; Chung, W. Bull. Korean Chem. Soc. 2003, 24(12), 1781.

15. Chung, Y.; Kim, B.; Hwang, J.; Kim, C. S. Microchem. J. 1999, 62,336 .

16. Martinez, D.; Pocurull, E.; Marcè, R. M.; Borrull, F.; Calull, M. Chromatographia 1996, 43(11-12), 619.

17. Pulg, D.; Silgoner, I.; Grasserbauer, M.; Barcel, D. Anal. Chem. 1997, 69, 2756.

18. Bigley, F. P.; Grob, R. L. J. Chromatogr. 1985, 350(2), 407. 